INTERNATIONAL JOURNAL OF MULTIDISCIPLINARY RESEARCH AND ANALYSis

ISSN(print): 2643-9840, ISSN(online): 2643-9875

Volume 04 Issue 01 January 2021

DOI: 10.47191/ijmra/v4-i1-06, Impact Factor: 5.522

Page No.- 38-45

\title{
Feed Additive of Binder Seaweed Grass in Fish Feed Formulation on Physical Characteristics and Efficiency
}

\author{
Kiki Haetami ${ }^{1}$, Abun ${ }^{2}$ \\ ${ }^{1}$ Faculty of Fisheries and Marine Science Padjadjaran University, Jalan Raya Bandung-Sumedang KM. 21, Sumedang-West Java \\ 45363, Indonesia \\ ${ }^{2}$ Faculty of Animal Husbandry, Padjadjaran University, Jalan Raya Bandung-Sumedang KM. 21, Sumedang-West Java 45363, \\ Indonesia
}

\begin{abstract}
The study was designed experimentally using a Completely Randomized Design, five treatments were repeated three times included the use of carboxymethyl cellulose as a control as much as $5 \%$, and the treatment of feed additives of seaweed as much as $5 \%, 75 \%, 10 \%$ and $12.5 \%$. The parameters measured were feed efficiency, rupture speed test, sink speed test, durability test, stability test and moisture content test using Analysis of Variance and continued with Duncan's Multiple Distance Test. The results showed that seaweed binder additive feed increased $(p<0.05)$ durability and stability in water, but did not show a significant difference ( $p>0.05$ ) on feed efficiency, breaking speed and sinking speed. Stability of pellets in water with the addition of seaweed binders of $10 \%$ is significantly higher $(p<0.05)$ than other pellets, i.e. after $10-60$ minutes ranging from $82.70 \%-97.40 \%$ with pellet durability of $98.24 \%$ and feed efficiency of $42.93 \%$.
\end{abstract}

KEYWORDS: binder, feed additives, fish feed efficiency, physical characteristics, seaweed grass.

\section{INTRODUCTION}

Feed is a combination of several ingredients that contain nutrients both quantitatively and qualitatively, which are needed to achieve optimum growth in accordance with genetic potential, the metabolic rate supported by feed energy content, temperature, and water quality. The thing that needs to be observed in feed formulation is the quality of raw materials and the compatibility of the nutrient composition contained in it according to the needs of the fish.

The quality and quantity of feed needs to be considered in supporting aquaculture. Feeds in catfish cultivation must have good physical and chemical qualities. Physical qualities include feed resistance, stability in water and breaking speed. While the chemical quality is the nutrient content in the feed. One form of artificial feed is pellets. Pellets are feed made by compacting, compacted through a mechanical process. Pellets can be made in the form of clumps and small cylinders of different diameters, lengths and levels of strength (Ensminger et al, 1990).

The physical quality of feed such as stability, buoyancy, and several other physical properties of feed need to be considered because the problems that often occur in pellet- shaped feed include the fragile and brittle forms when producing, distributing, and storing. Therefore, in the feed mixture there is a need for additional feed ingredients such as binders or adhesives. The adhesive can increase the physical quality of the feed in the form of pellets.

Binders or adhesives are ingredients that are added to feed formulas which function to unite all raw materials to make feed. The use of adhesives will affect the quality of feed physically. Adhesives are needed to bind components of feed ingredients so they have a compact structure so that they will not be easily broken. Adhesive can be divided into two types, namely natural adhesive and artificial adhesive. The most commonly used artificial adhesive is CMC (Carboxy Methyl Cellulose). However, if viewed from the aspect of CMC prices, it is considered less economical when used as an adhesive for fish feed because it is an imported raw material, therefore the use of natural adhesives is needed including flour, rice flour, corn flour, cassava peel (Retnani et al, 2010), tapioca flour, (Syamsu, 2007), palm kernel meal and seaweed flour (Saade \& Aslamyah, 2009) with good adhesive potential. On the other hand, natural adhesives use local raw materials so that they are easily available and affordable prices. Seaweed group of red algae that can be used as an adhesive is one of them is Kappaphycus alvarazii. Seaweed contains gel and 


\section{Feed Additive of Binder Seaweed Grass in Fish Feed Formulation on Physical Characteristics and Efficiency}

good nutrition, so it is often used as a basic ingredient in the production of carrageenan which is a long chain polysaccharide and has strong gel characteristics. The gel properties possessed by seaweed have the potential as adhesive material containing nutrients in the manufacture of pellet-type dry feed (Saade et al., 2013). To find out the effect of supplementary feed ingredients for nutritive seaweed on the physical characteristics and growth of fish, it is necessary to conduct research.

\section{MATERIALS AND METHODS}

This research was conducted at the Aquaculture Laboratory and Laboratory of Ciparanje Land Fisheries, Faculty of Fisheries and Marine Sciences, Padjadjaran University, West Java, Indonesia, which began in September 2018 until February 2019.

The feed material used fish meal, soybean meal, carboxy methyl cellulose, premix, rice bran and seaweed meal. The fish used in this study was the Siamese catfish with a length of $5-8 \mathrm{~cm}$ and 600 fishes and each aquarium was filled with 30 fish per aquarium.

The feed used was artificial feed with different Kappaphycus alvarazii seaweed binders, namely 5\%, 7.5\%, $10 \%$ and $12.5 \%$.

The research method was carried out experimentally using a Completely Randomized Design (CRD). This study used five treatments with three replications in each treatment. The treatments given were as follows:

A: feed with a CMC binder of $5 \%$ (Control)

B: feed with seaweed flour binders as much as $5 \%$ C: feed with seaweed flour binders as much as $7.5 \%$ D: feed with seaweed flour binders as much as $10 \% \mathrm{E}$ : feed with seaweed flour binder as much as $12.5 \%$.

\section{A. Research Procedure}

The preparation of the research tool began with cleaning the aquarium and checking the pellet making equipment. Aquarium rinsed using water, then dried and labeled according to treatment.

Preparation of pellets by providing raw materials for natural seaweed binders which were dried and milled then mixed with the other raw materials, namely bran, fish oil, premix and CMC.

Making test feed was done by preparing feed formulations according to protein requirements of $30 \%$ (Ghufran 2004) and the use of binders according to CMC 5\% treatment, Seaweed Flour 5\%, 7.5\%, 10\%, and 20.5\%. Treatment feed composition can be seen in Table 1.

Table 1. The composition of the treated feed.

\begin{tabular}{|c|c|c|c|c|c|}
\hline & $\begin{array}{c}\text { A } \\
(\text { CMC 5\%) }\end{array}$ & $\begin{array}{c}\text { B } \\
\text { (Seaweed grass 5\%) }\end{array}$ & C & (Seaweed grass 10\%) & $\begin{array}{c}\mathrm{E} \\
\text { (Seaweed grass 12,5\%) }\end{array}$ \\
\hline Fish meal & 20.54 & 20.67 & 19.30 & 19.85 & 16.67 \\
\hline Soybean meal & 20.54 & 20.67 & 19.30 & 19.85 & 16.67 \\
\hline Rice bran & 50.92 & 50.66 & 50.90 & 47.30 & 51.16 \\
\hline Premix & 2 & 2 & 2 & 2 & 2 \\
\hline Fish oil & 1 & 1 & 1 & 1 & 1 \\
\hline Seaweed meal & 0 & 5 & 7.5 & 10 & 12.5 \\
\hline CMC & 5 & 0 & 0 & 0 & 0 \\
\hline Sum & 100 & 100 & 100 & 100 & 100 \\
\hline
\end{tabular}

The making of feed was done through several processes, namely weighing, mixing raw materials, pelleting and drying. Mixing raw materials starts from the least to the most amount, then stirs until homogeneous. Materials that have been mixed are given as much as $6 \%$ water stirring until it becomes a mixture and then made pellet using hand pelletizer and dried using an oven. The physical test of pellet consisted of rupture speed, sinking speed, durability, stability of ration in water, and moisture.

Catfish seeds were kept for 30 days in an aquarium with a density of 30 fish / aquarium. The catfish weighed before stocking into the aquarium. Feeding frequency 3 times with the amount of feed given was $3 \%$ as daily feed intake. Measuring the weight of catfish was done every 6 days to determine the gain of catfish. On the last day the maintenance was carried out measuring of feed efficiency by observing the sum of feed intake and absolute weight growth. 


\section{Feed Additive of Binder Seaweed Grass in Fish Feed Formulation on Physical Characteristics and Efficiency}

\section{B. Research Parameters}

\section{Break Speed Test}

The rupture speed test was used to measure how long the feed destroyed in the water. The burst velocity test was observed visually (Saade and Alamsyah 2009).

\section{Sinking Speed Test}

The sinking speed test was carried out by measuring the length of time it takes the feed to move from the surface of water to the bottom. Pellets as many as 5 sticks were inserted into a measuring cup with a height of $20 \mathrm{~cm}$ from the surface of the water. The stopwatch was run just when the pellets were dropped on the surface of the water. Sinking speed was the distance divided by the time of the pellets through until the base of a measuring cup (Wulansari et al 2016).

\section{Durability Test}

Durability is the number of pellets that are returned intact after being stirred mechanically (pneumatic). According to Balazs et al. (1973) durability tests can be formulated as follows:

$$
\text { Durability }=\frac{\text { (Weight of pellets after rotating) }}{\text { (Weight of pellets before rotating) }} \times 100 \%
$$

\section{Stability of Ration in water}

Before dipping to be tested based on immersion time, the sample for each treatment was divided into three equal parts. The time of soaking times were 10, 30, 60 minutes, and then after immersion the pellets are removed and dried so that the moisture before soaking was the same as after. Dry weight and stability of the pellets were calculated according to Pascual and Tabbu (1979) and Sumalangkay (1981) research in Wulansari et al (2016), namely as follows:

$$
\begin{gathered}
\text { Moisture }=X+\frac{(Y-Z)}{Y} \times 100 \% \\
\text { Water Stability }=\frac{(\text { Final dry weight after soaking) }}{\text { (Initial dry weight before soaking) }} \times 100 \%
\end{gathered}
$$

Notes: Initial sample of Pellets $=\mathrm{A}$ gram (30 gram) Pellets + aluminum foil $=\mathrm{X}$ grams

(dry oven $105^{\circ} \mathrm{C}$ for 2 hours). Aluminum foil was issued and weighed $=\mathrm{Y}$ gram Pellet after drying ${ }^{*}=\mathrm{Z}$

\section{Feed Efficiency}

Feed Efficiency was calculated using the formula Zonneveld et al (1991) as follows:

$$
\text { Feed efficiency }=\frac{((W t+D)-W 0)}{(F)} \times 100 \%
$$

Notes: Wt : Fish biomass at the end of the study (g)

Wo: initial Fish biomass (g)

D: Weight of fish die during maintenance $(\mathrm{g})$

F: Amount of feed consumed (g)

\section{Data analysis}

The data obtained were then tabulated and analyzed using variance analysis (ANOVA) to determine the effect of each treatment. If there were differences between treatments then Duncan's multiple distance test was carried out with a confidence level of 95\% (Gasperz 1991).

\section{RESULTS AND DISCUSSION}

\section{A. Breaking Speed Test}

Breaking speed test serves to find out how long a feed fractures in water, the longer a feed breaks in water, the texture in the feed is very compact. 


\section{Feed Additive of Binder Seaweed Grass in Fish Feed Formulation on Physical Characteristics and Efficiency}

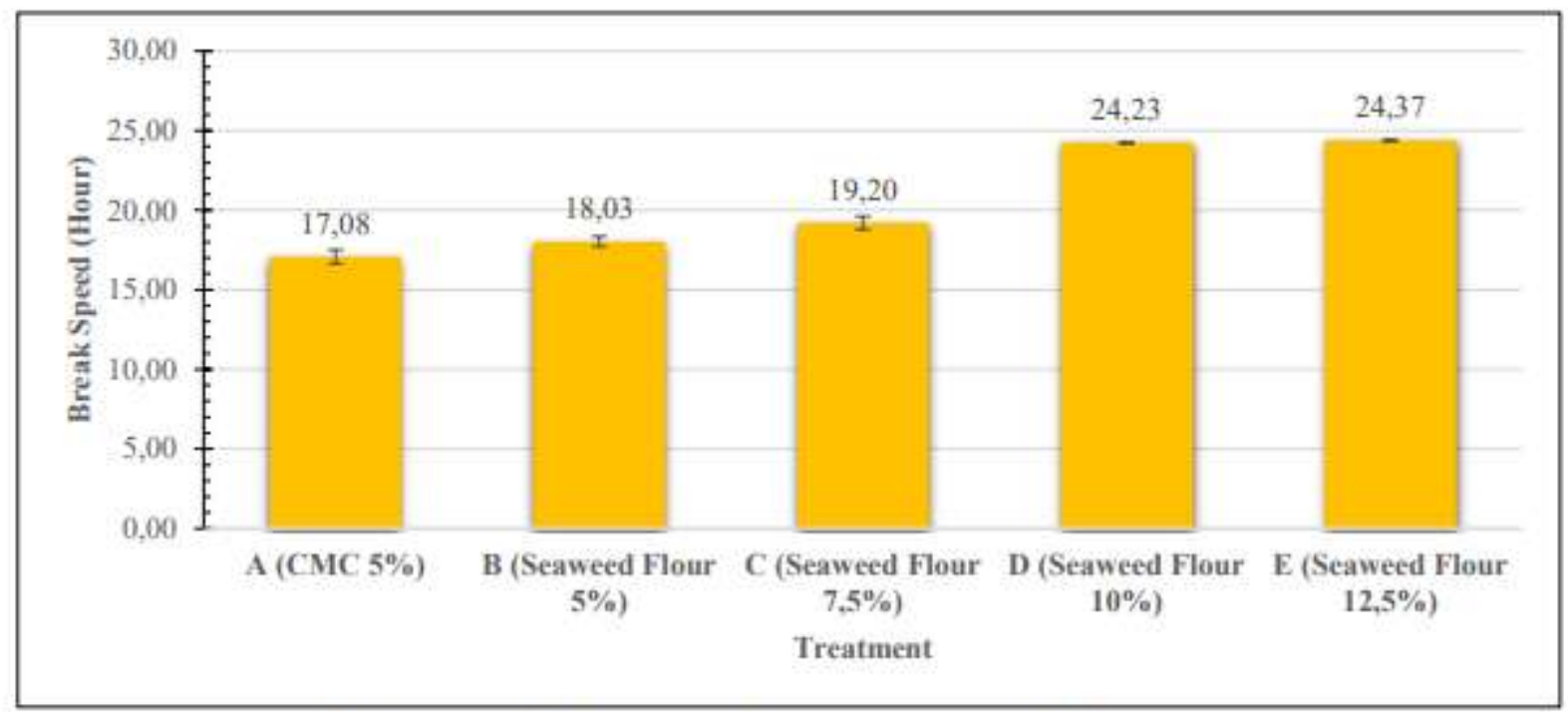

Figure 1. Graph of Breaking Speed of Seaweed Binders and CMC

Breaking speed on feed with the addition of natural seaweed binders Kappaphycus alvarazii each treatment produced different values. The range of breaking speed values in the treatment is between $17.08-24.37$ hours. The highest rupture velocity value was found in treatment $E$ with a burst velocity length of 24.37 hours, then under treatment $D$ with a breakdown speed of 24.23 hours, treatment $C$ with a breakdown speed of 19.22 hours, treatment B with a burst speed 18.03 hours and speed the lowest was found in treatment $A$ with a breakdown speed of 17.08 hours. The results of the analysis of variance showed that the addition of natural seaweed binders did not have a significant effect on each treatment.

The value of speed in the treatment of the addition of natural seaweed binaries Kappaphycus alvarazii belongs to a good value. This is in accordance with the results of Wulansari et al (2016) study that the speed of feed rupture with seaweed binders ranged between 22-23 hours. This is due to the influence of the agar content on seaweed which functions as a strong binder for the components of feed ingredients and makes the texture of the feed compact.

On the other hand, these properties maintain the nutrient content contained in the feed so that it is not easily dissolved in water and can be used by fish as an energy source. According to Yufera et al (2002) immersion for 5 minutes will cause the release of free amino acids by $8 \%$. There is a tendency for more levels of seaweed flour in feed, so the physical quality of feed will be better (Saade et al 2011).

\section{Sink Speed}

The sinking speed test is very important to find out how long it takes for feed when the surface of the water until the feed sinks and touches the bottom of the water. This will be closely related to the level of utilization of feed by fish. If for basic types of eating fish, the faster the speed of sinking, the higher the utilization of feed and vice versa for top-eating fish.

Based on the results of the sinking speed in Figure 4 the range of the sinking speed in the treatment is between $1.83-9.61 \mathrm{~cm} / \mathrm{s}$. The highest sinking speed was found in treatment B with a sinking speed of $9.61 \mathrm{~cm} / \mathrm{s}$, then below treatment A (control) with a sinking time of $3.75 \mathrm{~cm} / \mathrm{s}$, treatment $C$ with a sinking time of $3.65 \mathrm{~cm} / \mathrm{s}$, treatment $E$ with a sinking time of $2.08 \mathrm{~cm} / \mathrm{s}$ and the lowest sinking speed was found in treatment $D$ with a bursting speed of

$1.83 \mathrm{~cm} / \mathrm{s}$. The results of the variance analysis stated that the addition of natural seaweed binders did not have a significant effect on each treatment.

Table 2. Speed of Feed Sinks with Seaweed Binders and CMC

\begin{tabular}{|l|l|}
\hline Treatment & Sink Speed (cm/s) \\
\hline A (Control CMC 5\%) & $3,75 \pm 0,91^{\mathrm{a}}$ \\
\hline B (Seaweed Flour 5\%) & $9,61 \pm 7,37^{\mathrm{a}}$ \\
\hline C (Seaweed Flour 7,5\%) & $3,65 \pm 0,96^{\mathrm{a}}$ \\
\hline D (Seaweed Flour 10\%) & $1,83 \pm 1,17^{\mathrm{a}}$ \\
\hline E (Seaweed Flour 12,5\%) & $2,08 \pm 0,57^{\mathrm{a}}$ \\
\hline
\end{tabular}

Description: Values followed by lowercase letters that are the same show no significant difference at the $95 \%$ confidence level. 


\section{Feed Additive of Binder Seaweed Grass in Fish Feed Formulation on Physical Characteristics and Efficiency}

The high sinking speed in treatment B is due to the low level of adhesion between particles. This results in an easy process of infiltrating water particles into the feed so that the feed will sink quickly. The level of feed adhesiveness has a close relationship with the continuity offeed ingredients. Based on the velocity results, the other four treatments have a sinking speed lower than treatment B. The lowest sinking value among the four treatments is treatment D. In treatment D has a higher density between particles of feed raw material so that the gap in the feed is littler to be entered by water particles. According to Saade et al (2016) the speed of sinking in feed with seaweed compositions is influenced by the density due to hardening in feed, low density feed has a higher water content so it sinks quickly. This is in accordance with Newton II law, the density of a substance will affect the speed of sinking the substance (Yoon et al 2001).

\section{Feed Durability}

Durability is closely related to the level of feed resistance during production, distribution and storage. Fish feed can be said to have a good durability value of $>90 \%$ (Wulansari et al 2016). There are several factors that can affect the strength and durability of feed including the level of gelatinization of the raw materials used.

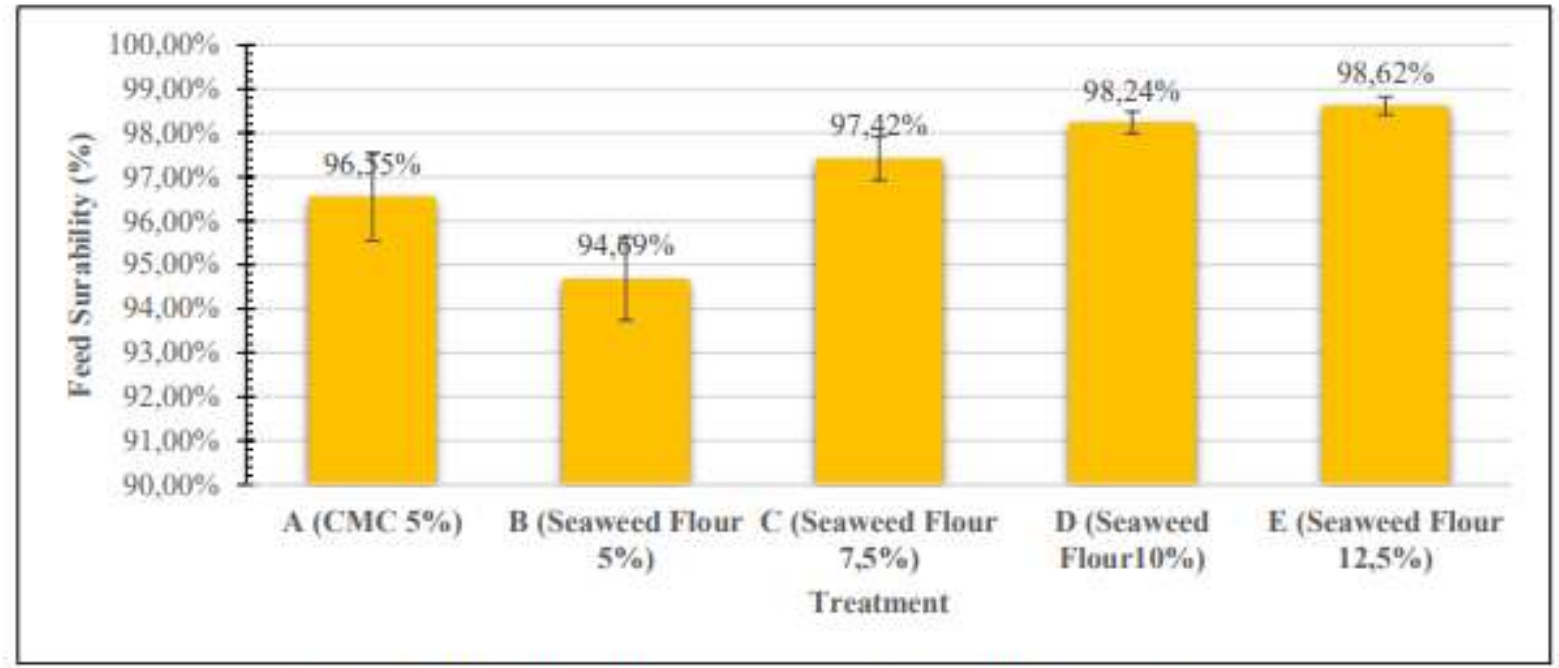

Figure 2. Feed Durability Test Graph with Seaweed Binder and CMC

Feed durability test is in the range of durability test values in the treatment which is between $94.69 \%-98.62 \%$. The highest durability test value is found in treatment $E$ with durability test results of $98.62 \%$, then under treatment $D$ with durability test value of $98.24 \%$, treatment $C$ with durability test value of $97.42 \%$, treatment $A$ (control) with durability test value $96.55 \%$ and the lowest durability test value is found in treatment B with a durability test value of $94.59 \%$. These results fall into the good category because the value of durability is $>90 \%$. The results of the analysis of variance on the durability test stated that the addition of natural seaweed binders produced a significantly different effect on the treatment

Table 3. Feed Durability Test with Seaweed Binders and CMC

\begin{tabular}{|l|l|}
\hline Treatment & Feed Durability (\%) \\
\hline A (Control CMC 5\%) & $96,55 \pm 0,0100^{\text {b }}$ \\
\hline B (Seaweed Flour 5\%) & $94,69 \pm 0,0095^{\text {a }}$ \\
\hline C (Seaweed Flour 7,5\%) & $97,42 \pm 0,0050^{\text {bc }}$ \\
\hline D (Seaweed Flour 10\%) & $98,24 \pm 0,0025^{\text {cd }}$ \\
\hline E (Seaweed Flour 12,5\%) & $98,82 \pm 0,0020^{d}$ \\
\hline
\end{tabular}

Description: Values followed by lowercase letters that show the same are not significantly different at the $95 \%$ confidence level.

Treatment E (12.5\% Seaweed Flour) has the highest durability value that is equal to $98.82 \%$ when compared to other treatments. Seaweed has a very strong gel characteristic so that it can attach very well to the feed-piercing materials. This seaweed is a long chain polysaccharide that has strong gel characteristics for adhesives in the manufacture of pellet-type dry feed (Saade et al., 2013). Saade et al (2011) stated that the G.gigas seaweed binder was able to bond all particles of feed raw materials into a more compact and interconnected each other so that it has a very good hardness. Feed with a high durability value does not necessarily have good nutritional value, because it is not only determined by the physical or chemical properties 


\section{Feed Additive of Binder Seaweed Grass in Fish Feed Formulation on Physical Characteristics and Efficiency}

of feed but by the biological test of the organism. Treatment $E$ has the highest value on the durability test but at the daily growth rate (Table 2 ) has a low value.

Good quality feed can be easily digested and produce good energy for fish. Treatments B and C have lower feed efficiency compared to treatment $D$, but do not show significant differences. This is because in treatment $B$ and $C$ the level of adhesion between feed ingredients is not good so that when the feeding process in the cultivation media there are some foods that are easily dissolved in water. Dissolved feed in the culture medium cannot be used by catfish seeds, especially for the process of converting feed into energy for fish growth. The value of fish growth rate in treatment $\mathrm{E}$ was higher than treatment $\mathrm{A}$ (control) and lower than treatment B, D and D. This is because the feed in treatment $E$ had a higher lavel violence among all treatments. The high durability in treatment $\mathrm{E}$ results in food difficult to digest by the digestive tract in fish so that the energy obtained from feed is not sufficient for fish growth. According to NRC (2011) states the energy obtained from feed is used by fish for basic metabolism, production of sexual organs, movement, replacement of damaged cells, and the rest is used for growth of the body.

\section{Absolute Weight}

Absolute growth is an increase in both the length and weight of fish at a certain age. According to Effendi (2004) absolute weight growth is the difference between the total body weight of the fish at the end of maintenance and the beginning of maintenance. The results of the observation showed that the absolute range of fish weight by giving natural Kappaphycus alvarazii seaweed flour feed was 48.00-88.67 grams.

Table 4. Absolute Weight Test with Seaweed Binders and CMC

\begin{tabular}{|l|l|}
\hline Treatment & Absolute Weight (gr) \\
\hline A (Control CMC 5\%) & $50,33 \pm 16,15^{a}$ \\
\hline B (Seaweed Flour 5\%) & $51,67 \pm 15,95^{a}$ \\
\hline C (Seaweed Flour 7,5\%) & $51,00 \pm 26,21^{a}$ \\
\hline D (Seaweed Flour 10\%) & $88,67 \pm 31,18^{a}$ \\
\hline E (Seaweed Flour 12,5\%) & $48,00 \pm 22,87^{a}$ \\
\hline
\end{tabular}

Description: Values followed by lowercase letters that are the same show no significant difference at the $95 \%$ confidence level.

Based on the results of the analysis of variance, it was shown that the use of natural seaweed binders Kappaphycus alvarezii did not have a significant effect on the feed efficiency of the average catfish seed. Treatment $D$ and $A$ have higher feed efficiency values compared to treatment B, treatment C, and Treatment E. Efficiency of feed on catfish seeds is in the range of $25.74 \%$ to $42.93 \%$.

The highest value is found in D treatment with a feed efficiency value of $42.93 \%$ and the lowest feed efficiency value at treatment $\mathrm{E}$ of $24.54 \%$. This feed efficiency value is still below the category of poor feed efficiency or can be said to be low. This is in accordance with Craig and Helfrich (2002) that a good feed category has a feed efficiency value of more than $50 \%$ or close to $100 \%$.

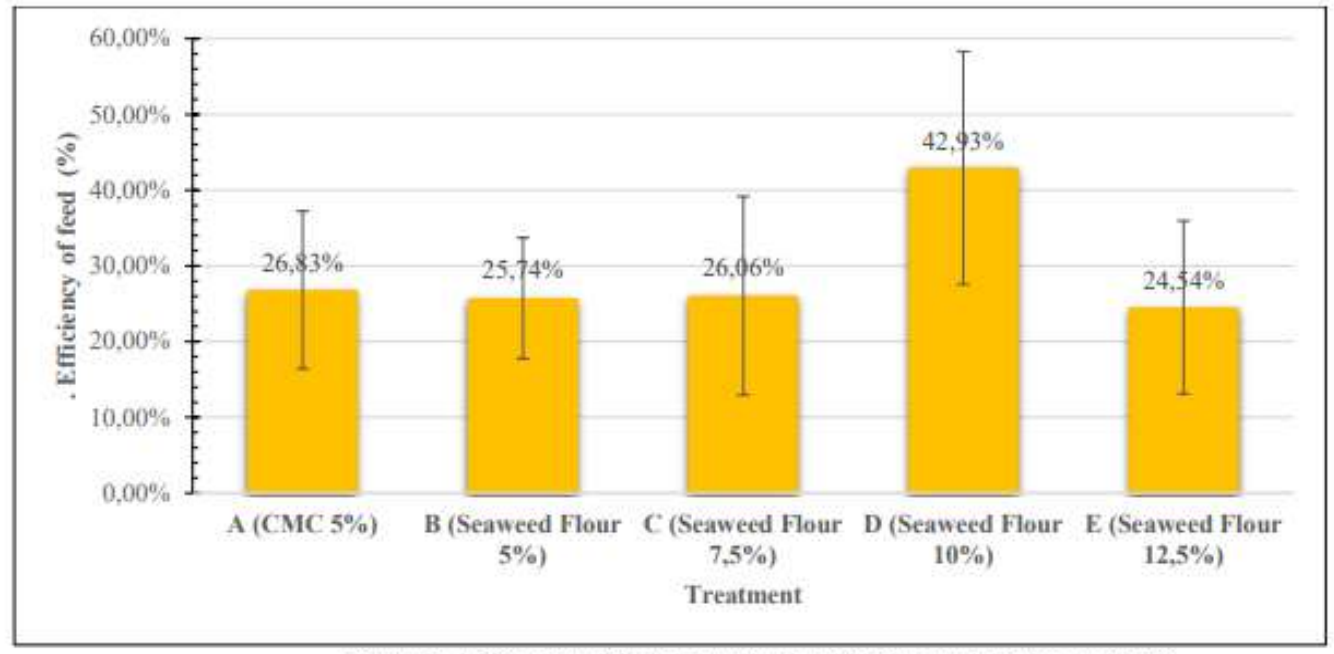

Figure 3. Efficiency of feed Test Graph with Seaweed Binder and CMC 


\section{Feed Additive of Binder Seaweed Grass in Fish Feed Formulation on Physical Characteristics and Efficiency}

Low feed efficiency is thought to be due to the use of vegetable raw materials whose composition is more than needed, namely the use of soybean meal raw materials. The raw material for soybean meal affects the digestion rate of feed. This is caused by a high content of soybean meal containing oligosaccharide compounds which are difficult to digest. According to Storebakken et al (2000) digestibility in fish fed with soybean meal contains ingredients that are difficult to digest because soybean meal contains $30 \%$ carbohydrates with oligosaccharide compounds reaching $10 \%$. Based on Aliyah (2017) these components are difficult to digest and are absorbed by fish that are monogastric animals. In addition, catfish are omnivorous animals tend to be carnivorous, so they are more likely to eat animal raw materials. According to Handajani and Widodo (2010) states that feed ingredients derived from animal products are generally easier to digest than vegetable products. In addition, it is suspected that there is an increase in crude fiber derived from bran feed raw materials. According to Haetami and Sukaya (2004) the increase in crude fiber content will accelerate the rate of travel of food in the digestive tract which results in a decrease in the chance of the gastrointestinal tract digesting food substances.

\section{CONCLUSIONS}

Used of seaweed flour $10 \%$ had higher water stability after two hours in water compared to basal pellets without binders of seaweed (CMC 5\%). It improved feeds water stability is one important reason why seaweed grass enhances fish growth. The use of natural seaweed binders Kappaphycus alvarezii did not have a significant effect on the feed efficiency of the average catfish seed.

\section{REFERENCES}

1) Andi, P, S, I. 2011. Proximate Analysis of Feeds Using Binders of Kappaphycus alvaezii Seaweed on Tilapia Synthesis and Growth. Agris journal system. $7(1)$

2) Balazs GH, Ross E, Brooks CC. 1973. Preliminary studies on the preparation and feeding of crustaceans diets. Aquaculture 8: 755 - 766.

3) Bathnagar, A. and P. Devi. 2013. Water Quality Guidlines for Management of Pound Fish Culture. International Journal of Environmental Science 3 (6) 1980 - 2009.

4) Djunaidah, IS, MR Toieliher., MI Effendie., S Sukimin., And E. Riani. 2004. Growth and Survival of Mangrove Crab Seeds (Scylla paramamosain) Maintained in Different Substrates. Journal of Marine Sciences, 9 (1) 20 - 25.

5) Ekubo, A, A.dan J, F, N. Abowei. 2011. Review of Some Water Quality Management Principles in Culture Fisheries. Journal of applied Sciences, Engineering and Technology. 3 (2) 1342 - 1357.

6) Jaelani, A., S, Dharmawati., Wacahyono. 2016. Effect of Stacks and Duration of Save Pellet Feed on Physical Quality. Ziraa'ah Journal. 41 (2); 261 - 268.

7) Joko, Muslim and Ferdinan.2013. Nursing of Tambakan Fish larvae (Helostoma temminchi) with different stocking densities. Journal of fisheries and marine affairs. 18 (2) 59 - 67.

8) M, Yufera., S, Kolkovski., C, Fernandez., K, Dabrowski. 2002. Free Amino Acid Leaching from a Protein-Walled Microencapsulated Diet For Fish Larvae. Journal of Aquaculture. 214 (4): 273-287.

9) Minggawati I, Saptono. 2012. Water Quality Parameters for Siamese Fish (Pangasius pangasius) in the Kahayan River Cage, Palangkaraya City. Journal of Tropical Animal Science. 1 (1).

10) Personal, R. Edison Saade, Haryati Tandipayuk.2016. Effect of Hardening Method on Physical and Chemical Quality of Feed Gel Koi Fish Cyprinus carpio haematopterus Using Kappaphycus alvareziis Seaweed Flour as Thickener. Indonesian Seaweed Journal. 1 (2) 108 - 116.

11) Retnani, Y., N. Hasanah, Rahmayeni, and L. Herawati. 2010. Test of Physical Properties of Pellet-Shaped Broiler Chicken Rations Added by Ongok Adhesives Through Water Spraying Process. Agripet 10 (1) 13-18.

12) Saade, E. and S. Aslamyah. 2009. Physical and Chemical Test of Artificial Feed for Shrimp of Penaeus monodon Fab. Using Various Types of Seaweed as Adhesive. Torani (Journal of Marine and Fisheries Sciences). 19 (2): 107-115.

13) Saade, E. S, Aslamyah, and N, I, Salam. 2011. Quality of Artificial Shrimp Windu Feed Using Various Doses of Seaweed Flour (Gracilaria gigas) As Adhesive. Indonesian Aquaculture Journal. 10 (1): 59 -66.

14) Syamsu, JA 2007. Physical Characteristics of Feed Ducks in the Form of Pellets Given Different Adhesives and Different Storage Lengths. Animal Science Journal. 7 (2) 128-134.

15) Tahapari, E. and J. Darmawan. 2018. Feed Protein Needs for Optimal Performance of Pasupati Siamese Fish Seeds (Pangasiid). Journal of Aquaculture Research. 13 (1) 47 - 56.

16) Utomo, NBP, Susan., M Setiawati. 2013. Role of Fish Flour from Various Raw Materials on Sangkuriang Clarias sp. Indonesian Aquaculture Journal. 12 (2) 158-168. 


\section{Feed Additive of Binder Seaweed Grass in Fish Feed Formulation on Physical Characteristics and Efficiency}

17) Wulansari, R., Y, Andriani., K, Haetami.2016. Use of Binder Types on Physical Quality of Shrimp Feed. Journal of Marine Fisheries. 7 (2) 140-14.

18) Yoon, WD, SK Kim and KN Han. 2001. Morphology and Sinking Velocities of Fecal Pellets of Copepod, Molluscan, Euphausiid, and Salp Taxa in The Nortehastern Tropical Atlantic. J. Marine Biology, (139) 923-928. 